\title{
O PAPEL DO DIRETOR NA PERSPECTIVA DO PLANEJAMENTO ESTRATÉGICO DE UMA GESTÃO ESCOLAR
}

http://dx.doi.org/10.5902/2318133826054

\author{
Manoela Atarão da Rocha Saldanha \\ Centro Universitário Ritter dos Reis, Brasil. \\ Cristine Hermann Nodari \\ Universidade Feevale, Brasil. \\ Julice Salvagni \\ Universidade do Vale do Rio dos Sinos, Brasil.
}

\begin{abstract}
Resumo
O presente artigo apresenta um estudo de caso realizado nos colégios da Rede Marista. $O$ objetivo da pesquisa foi compreender o papel e a influência do diretor escolar na execução do planejamento estratégico. Para atingir este objetivo foram estudados os conceitos da gestão educacional com ênfase na liderança do diretor escolar e a compreensão de planejamento estratégico do ponto de vista de sua execução. A coleta e dados foi realizada por meio de pesquisa documental e entrevistas semiestruturadas, que foram aplicadas e quatro gestores dos colégios da Rede Marista, sendo dois deles gestores da estrutura executiva e os outros dois diretores. Ao analisar os dados foi possível conhecer e entender o planejamento estratégico dos colégios da Rede Marista, identificar as atribuições legais e civis de um diretor escolar, além de compreender o perfil de cargo e a influência do diretor escolar como gestor principal da execução do planejamento estratégico de seu colégio e da Rede Marista.

Palavras-chave: planejamento estratégico, colégios da rede marista, gestão educacional, diretor escolar.
\end{abstract}

\section{THE ROLE OF THE DIRECTOR IN THE PERSPECTIVE OF THE STRATEGIC PLANNING OF A SCHOOL MANAGEMENT}

\begin{abstract}
This article presents a case study realized in the Marista Schools Network. The research goal is understanding the role and the influence of the school principal in the execution of the strategic planning. In order to reach this goal, some concepts were studied envolving educational management focusing in the leadership of the principal and the comprehension of the strategic planning at the moment of its execution. Data collection was made through documental research and semistructured interviews, which were applied considering four managers of the Marista Schools Network, being two of them top executive managers and two of them principals. Through the data analysis it was possible knowing and understanding the job profile and the influence of the principals as main leaders, facing the implementation of the strategic planning in their school and also considering the Marista Network as a whole.
\end{abstract}

Key-words: strategic planning, Marista Schools, educational management, school principal. 


\section{Introdução}

s instituições de ensino, sobretudo aquelas de educação básica, passaram
por inúmeras mudanças relacionadas a gestão organizacional nos últimos
anos. Na década de 1990 o cenário das escolas privadas no Brasil era favorável no que se refere a captação de estudantes, ou seja, a demanda era maior que a oferta. Sendo assim, estas instituições não se preocupavam com questões mercadológicas, como a qualidade de atendimento, por exemplo, mas baseavam seu crescimento e manutenção na tradição educacional de seus serviços. Entretanto, o cenário atual revela que este viés foi invertido e agora as escolas é que buscam pelas famílias (Corus consultores, 2013).

Partindo desta nova realidade a profissionalização da gestão tornou-se pauta principal nas instituições de ensino, principalmente nas escolas de confissão católica. Com isto, o projeto pedagógico depende de uma gestão empresarial eficaz para atender este novo modelo. Do ponto de vista da alta gestão o diretor escolar é o gestor no universo de uma escola, é ele quem aponta os caminhos administrativos e pedagógicos a serem seguidos pela equipe educativa e administrativa. Para Lück (2010) a função de gestor escolar, neste caso abordando o cargo de diretor geral, tem um papel característico de liderança, já que ele é protagonista da mobilização, coordenação e orientação dos os agentes da comunidade escolar. Assim, na educação escolar, a liderança é um processo compartilhado.

Muitos autores destacam a importância de uma liderança que avaliza o planejamento estratégico (Tregoe e Zimmerman, 1984; Ulrich, 2001; Bossidy, 2005; Hrebiniack, 2006). Assim, em se tratando da eficácia do método, é fundamental que a liderança seja voltada à execução (Semler, 1988; Freitas, 1991; Pereira e Cunha, 2004; Bossidy e Charan, 2002; Hrebiniack, 2006).

Apesar de haver inúmeros estudos na área da administração que contribuem para a elaboração do planejamento estratégico institucional, muitos gestores se deparam com a dificuldade de implantar e executar aquilo que foi definido, etapa em que grande parte dos planejamentos entram em falência (Kich et al, 2008). Esta situação não é diferente no ambiente educacional, em especial nas escolas privadas.

Tendo em vista a conjuntura acima indicada e levando em conta as variáveis que permeiam a função do diretor escolar, a problemática abordada no presente trabalho é a seguinte: qual o papel e a influência do diretor geral escolar em relação ao planejamento estratégico? Desta forma, esta pesquisa teve como objetivo principal compreender o papel e a influência do diretor escolar na execução do planejamento estratégico. Foram definidos como objetivos específicos os seguintes: identificar os elementos do planejamento estratégico e as principais atribuições do diretor escolar dos colégios da Rede Marista, além de mapear o perfil do diretor escolar marista, visando à execução do planejamento estratégico.

O presente trabalho apresenta uma visão administrativa em relação à gestão educacional, a qual é mais comumente estudada dentro de um viés pedagógico. Do mesmo modo, buscar a identificação do papel e influência do diretor escolar na execução do planejamento estratégico, sob a ótica administrativa, poderá contribuir para a profissionalização da gestão dentro do mercado da educação privada e confessional. 


\section{Gestão educacional}

Do ponto de vista social a educação pode ser conceituada como uma ferramenta que auxilia a desenvolver a humanidade, já que ocorre a partir da troca de conhecimentos, criando um conjunto de ideias e credos, de qualificações e especialidades, abarcando bens e poderes que, juntos, moldam a sociedade (Brandão, 1993). Observando a dimensão individual é importante perceber o estudante como agente fundamental do processo de aprendizagem. Assim, o estudante não é o objetivo do ensino, mas sujeito protagonista do processo (Demo, 1996).

A reorganização das funções organizacionais das escolas nas últimas décadas trouxe à tona a preocupação administrativa e gerencial de suas ações. As redes de ensino básico buscam estratégias para gerir suas escolas com vistas a alcançar eficácia educativa (Libâneo, 2004). O mesmo autor destaca que a gestão educacional busca a prover todas as condições, meios e recursos que garantam o andamento do processo de ensino e aprendizagem. A gestão educacional foi concebida para determinar a orientação e motivação do sistema educativo

Sob ótica da gestão escolar, Lück (2009) entende que a escola é

uma organização social constituída pela sociedade para cultivar e transmitir valores sociais elevados e contribuir para a formação de seus alunos, mediante experiências de aprendizagem e ambiente educacional condizentes com os fundamentos, princípios e objetivos da educação. $O$ seu ambiente é considerado de vital importância para o desenvolvimento de aprendizagens significativas que possibilitem aos alunos conhecerem o mundo e conhecerem-se no mundo, como condição para o desenvolvimento de sua capacidade de atuação cidadã. (p. 20)

Sendo assim, a gestão escolar é uma parte da gestão educacional e a partir dela pode-se observar a escola e as dificuldades organizacionais e educacionais globalmente, buscando ações interligadas estrategicamente para o alcance dos objetivos centrais da instituição. A gestão escolar tem o foco profissional nos aspectos do gerenciamento: planejamento, organização, liderança, orientação, monitoramento e avaliação (Luck, 2009).

No contexto escolar o direcionamento da gestão está diretamente ligado à capacidade das pessoas em dirigir e controlar as organizações. Sendo assim, é possível dizer que as pessoas são os principais atores das organizações e que todas as atividades dentro das corporações são comandadas por pessoas, as quais buscam a maximização de resultados para o negócio e procuram satisfazer suas necessidades (Lacombe, 2005).

Ao diretor escolar cabe a responsabilidade de garantir que a escola cumpra sua missão: "ser um lugar de educação, entendida como elaboração do conhecimento, aquisição de habilidades e formação de valores" (Gomes, 2003, p. 47). Esta finalidade da educação é dependente de uma gestão administrativa eficiente, eficaz e efetiva, que vise à sustentabilidade da instituição. Desta forma o diretor escolar, como gestor principal da escola, deve assegurar o exercício da liderança.

A conceituação do termo liderança é uma questão polêmica. Esse fenômeno pode ser entendido da mesma forma que a beleza é definida por Bennis (1996), ou seja, algo difícil de definir, mas fácil de reconhecer. Katz e Kahn (1987) relatam que este é o termo 
mais utilizado no âmbito organizacional e que, provavelmente, nenhum outro tenha sido utilizado com tantos significados e aplicações diferentes. Portanto, qualquer esforço para definir esta palavra pode ser arbitrário e subjetivo

Do ponto de vista genérico é possível dizer que a liderança é um processo social, estabelecido pelas pessoas a partir da influência mútua das relações. No caso de líderes e liderados é fácil observar este movimento em diversos espaços sóciais: política, trabalho, esporte, famílias, organizações, entre outros. Independentemente das unidades sociais é fundamental ressaltar que todas as pessoas são capazes de influenciar seus semelhantes, ou seja, todas as pessoas possuem potencialidades para exercer liderança (Limongi-França; Arrelano, 2002).

Apesar da possibilidade de qualquer pessoa ser um líder, a maestria da liderança é prerrogativa de poucos. Handy (1996) destaca algumas características importantes para o sucesso no ato de liderar: crença em si mesmo, dúvida razoável, paixão pelo trabalho, consciência de outras realidades, amor pelas pessoas e capacidade para a solidão. Já para Grün (2006) a liderança é uma atividade participativa, sendo que líderes e liderados se complementam e a liderança só acontece se o liderado se deixar liderar. Para o autor este processo não depende somente do líder e sim da participação de quem a aceitará.

Hunter (2006, p. 18), por exemplo, aborda um conceito de liderança global, destacando o ato de liderar como "a habilidade de influenciar pessoas para trabalharem entusiasticamente visando atingir objetivos comuns, inspirando confiança por meio da força do caráter".

No contexto escolar existe uma equipe de gestores que compartilha o ato de gerir a escola e suas várias dimensões. Supervisores, orientadores e coordenadores são alguns dos cargos que compõem a equipe diretiva de muitos colégios. Entretanto, o diretor é o profissional que representa a liderança máxima de uma escola, portanto, o seu perfil de atuação impacta toda a comunidade escolar (Lück, 2009). Ainda de acordo com a autora, o diretor é a representação de um mentor e orientador de toda a vida da escola, seus processos e entregas. Apesar de, juntamente com sua equipe de educadores, gerir a rotina escolar, o diretor não pode diluir a sua responsabilidade entre os demais membros da instituição. Desta forma, sua maior dificuldade é manter a equidade entre os aspectos pedagógicos e administrativos, principalmente no cenário da educação privada.

É importante destacar que o diretor deverá observar os elementos da gestão para dirigir sua escola rumo à sustentabilidade financeira, porém, a principal atribuição deste gestor líder é a garantia de uma educação de excelência acadêmica e formação de cidadãos. Lück (2009), a partir desta abordagem, destaca o papel do diretor como

o profissional a quem compete a liderança e organização do trabalho de todos os que nela atuam, de modo a orientá-los no desenvolvimento de ambiente educacional capaz de promover aprendizagens e formação dos alunos, no nível mais elevado possível, de modo que estejam capacitados a enfrentar os novos desafios que são apresentados. (p. 17)

Pensando no espaço-tempo escolar Menossi et al. (2012), aponta que o diretor precisa compreender seu papel de líder no sentido de encaminhar o grupo de um ponto à outro, a partir de ações estratégicas e motivadoras que incentivem o trabalho em equipe com foco no aprimoramento dos pontos fortes e diminuição das fraquezas do seu colégio. 


\section{Planejamento estratégico}

Mintzberg, Ahlstrand e Lampel (2007) destacam que a palavra estratégia é alvo de muitos estudos e ponto alto nas discussões corporativas. Normalmente a estratégia é representada por um plano ou algo equivalente, todavia os autores mencionados abordam o a partir de cinco dimensões: plano, pretexto, padrão, posição e perspectiva, ou seja, "consistência em comportamento ao longo do tempo" (p. 17). A estratégia pode ser definida como a forma de conceber e prospectar o futuro, junto ao processo de tomada de decisão, embasada em procedimentos formais que gerem resultados.

Para bem entender o planejamento estratégico, além da estratégia, é preciso compreender o ato de planejar. Peterson e Tiffany (1998) definem o planejamento como uma estratégia para alavancar a probabilidade de sucesso da organização inserida em um mundo de constantes transformações. O planejamento é um "método de ordenação de atividades com vistas a alcançar objetivos propostos, ou seja, atingir um futuro desejado" (Tachizawa; Rezende, 2000, p.33). Neste sentido, é possível dizer que o planejamento antecede a ação, já que este processo visa a estabelecer um estado futuro por delineamentos de atividades e dos meios efetivos para torná-lo realidade (Oliveira, 2008).

Pensando na prospecção de futuro é fundamental destacar que o planejamento estratégico não é uma garantia daquilo que dará certo ou errado, mas uma preparação para situações desconhecidas, facilitando a ação da empresa em diferentes cenários (Peterson; Tiffany, 1998). Sendo assim, o planejamento estratégico trata de futuros prováveis, permitindo a adoção de técnicas e ferramentas lógicas com base na trajetória da organização, onde há grande possibilidade de alcançar aquilo se deseja (Tachizawa; Rezende, 2000).

Oliveira (2008) conceitua o planejamento estratégico como um "processo administrativo que proporciona sustentação metodológica para se estabelecer a melhor direção a ser seguida pela empresa" (p. 48). Neste sentido é importante salientar que o planejamento estratégico tem o objetivo de interagir com o mercado para garantir uma atuação diferenciada e inovadora.

Ainda nesta linha, Almeida (2013) define o planejamento estratégico a partir de uma perspectiva sistêmica:

Planejamento estratégico é uma técnica administrativa que procura ordenar as ideias das pessoas, de forma que possa criar uma visão do caminho que se deve seguir (estratégia). Depois de ordenar as ideias, são ordenadas as ações, que é a implementação do Plano Estratégico, para que, sem desperdício de esforços, caminhe na direção pretendida. (p. 13)

Apesar de sua característica menos flexível, o planejamento estratégico precisa ser implantado e executado. Whittington (2002) relata que, por mais que as estratégias estejam bem elaboradas e o plano estratégico sistematizado, tendem a fracassar se não forem bem implementadas. A incapacidade e a indisciplina dos gestores para transformar as ideias em ação é a principal causa do insucesso dos planejamentos estratégicos (Bossidy, 2005). 
A responsabilidade para implementar o planejamento estratégico é dos altos níveis hierárquicos da organização (Oliveira, 2008). Logo, a liderança tem um papel fundamental na execução das estratégias, já que determina de que maneira a empresa responderá aos seus desafios (Hrebiniak,2006).

A presença do líder na execução do planejamento estratégico aumenta a probabilidade de sucesso da metodologia, já que se entende que um gestor principal tenha conhecimento apurado do seu negócio e seja capacitado para motivar e influenciar pessoas. Apesar de parecer uma tarefa simples a liderança executora é uma habilidade difícil de dominar e de se encontrar nas empresas, embora seja ela que leve a empresa até o alcance de seus objetivos (Bossidy, 2005).

Para Hrebiniak (2006) o desafio do líder na implantação do planejamento estratégico é a sua própria execução. Ao mesmo tempo que ele é fundamental na elaboração dos objetivos da empresa, também precisa converter estas aspirações em ações, realizá-las e acompanhá-las. Por isso, neste processo de implantação do planejamento estratégico, o líder é um elemento crucial (Csikszentmihaly, 2001).

\section{Metodologia}

Levando-se em conta os objetivos propostos, este artigo pode ser definido como uma pesquisa exploratória que foi aplicada para constatar a causa de um problema (Boone e Kurtz, 1998). De acordo com Roesch (2005), como opção metodológica, a pesquisa qualitativa pode ser pertinente para todo o tipo de projeto, já que possui um caráter exploratório. Ainda sobre a pesquisa qualitativa é fundamental levar em conta que muitos dos resultados e conclusões obtidos dependem do horizonte teórico do pesquisador, já que a abordagem qualitativa tem natureza subjetiva (Zikmund, 2006).

Neste trabalho utilizou-se o estudo de caso como método de trabalho. O estudo de caso é uma proposta que busca investigar um fenômeno dentro de seu presente contexto (Yin, 2005). Esta estratégia possui característica de grande flexibilidade, dificultando indicar um roteiro rígido para o desenvolvimento da pesquisa (Gil, 1996).

De acordo com Marconi e Lakatos (2007) a etapa de coleta de dados é a fase em que se começa a aplicação dos instrumentos elaborados e das técnicas selecionadas. No estudo de caso, esta coleta é feita com o auxílio de diversos procedimentos, não sendo obrigatória a utilização de apenas um modelo de coleta de dados (Roesch, 2005). Para um estudo de caso as entrevistas são consideradas como fonte indispensável de evidências, justamente pelo fato de que a investigação social normalmente se relaciona com atividades de pessoas e grupos (Yin, 2005).

Marconi e Lakatos (2002) definem a entrevista como o encontro de duas pessoas, com intuito de uma delas obter informações sobre um determinado tema. Este procedimento é utilizado em pesquisa social para coleta de dados ou como auxílio na conclusão e desdobramentos de um problema social.

O presente artigo utiliza o método de entrevista semiestruturada e análise documental para investigação de seu problema. $\mathrm{Na}$ entrevista semiestrutura é fundamental a preposição de perguntas abertas, organizadas em categorias, a fim de excluir as predeterminações do pesquisador. A mesma autora diz que a análise de documentos é uma das fontes mais utilizadas em trabalhos de Administração, sendo feita por meio de relatórios da organização, materiais utilizados em relações públicas, 
documentos legais, declarações, entre outros. Este tipo de pesquisa complementa a entrevista ou outras formas de coleta (Roesch, 2005). A pesquisa documental foi realizada pela análise de manuais da organização, políticas, publicações literárias, periódicos de autoria da organização, websites, material de divulgação entre outros documentos que demonstrarem relevância para o projeto no decorrer da pesquisa.

O estudo foi desenvolvido nos colégios da Rede Marista, com vistas a identificar o papel e a influência do diretor escolar na execução do planejamento estratégico. A população envolveu dois gestores - superintendente e gerente educacional - dos colégios da Rede Marista, bem como os dezoito diretores das escolas da Rede.

A entrevista semiestruturada foi aplicada ao superintendente dos colégios da Rede Marista, responsável geral pelo planejamento estratégico da rede, ao gerente educacional dos colégios da Rede Marista, gestor principal operacional dos colégios, ao diretor do Colégio Marista Ipanema e à diretora do Colégio Marista Champagnat, todos atuantes de unidades de Porto Alegre - RS. O quadro 1 descreve as principais características dos entrevistados, selecionados levando em conta a sua capacidade em definir o papel e a influência do diretor na execução do planejamento estratégico.

Quadro 1 -

Perfil dos elementos entrevistados.

\begin{tabular}{|l|l|l|l|l|}
\hline \multicolumn{1}{|c|}{ Cargo } & Idade & $\begin{array}{l}\text { Tempo de } \\
\text { empresa }\end{array}$ & \multicolumn{1}{c|}{ Formação } & \multicolumn{1}{c|}{$\begin{array}{l}\text { Experiência na Rede } \\
\text { Marista }\end{array}$} \\
\hline $\begin{array}{l}\text { Superintendente } \\
\text { dos Colégios da } \\
\text { Rede Marista }\end{array}$ & 57 anos & 3 anos & $\begin{array}{l}\text { Graduação em } \\
\text { Administração; } \\
\text { mestrado em } \\
\text { Administração. }\end{array}$ & Cargo atual \\
\hline $\begin{array}{l}\text { Gerente } \\
\text { educacional dos } \\
\text { Colégios da Rede } \\
\text { Marista }\end{array}$ & 31 anos & 15 anos & $\begin{array}{l}\text { Graduação em } \\
\text { Filosofia; } \\
\text { especialização em } \\
\text { Gestão Educacional; } \\
\text { MBA em Gestão } \\
\text { Empresarial; } \\
\text { mestrado em } \\
\text { Educação. }\end{array}$ & $\begin{array}{l}\text { lrmão Marista; } \\
\text { diretor do Colégio } \\
\text { Marista Vetorello e } \\
\text { Colégio Marista Graças; } \\
\text { coordenador educacional } \\
\text { dos Colégios da Rede } \\
\text { Marista. }\end{array}$ \\
\hline $\begin{array}{l}\text { Diretor do } \\
\text { Colégio Marista } \\
\text { Ipanema }\end{array}$ & 43 anos & 25 anos & $\begin{array}{l}\text { Graduação em } \\
\text { Educação Física; } \\
\text { especialização em } \\
\text { Gestão Curricular. }\end{array}$ & $\begin{array}{l}\text { Professor no Colégio } \\
\text { Marista Santa Maria; } \\
\text { coordenador de turno no } \\
\text { Colégio Marista Santa } \\
\text { Maria; } \\
\text { vice-diretor no Colégio } \\
\text { Marista Santa Maria; } \\
\text { diretor do Colégio } \\
\text { Marista. }\end{array}$ \\
\hline
\end{tabular}




\begin{tabular}{|l|l|l|l|l|}
\hline $\begin{array}{l}\text { Diretora do } \\
\text { Colégio Marista } \\
\text { Champagnat }\end{array}$ & 47 anos & 28 anos & $\begin{array}{l}\text { Graduação em } \\
\text { Pedagogia; } \\
\text { especialização em } \\
\text { Psicopedagogia; } \\
\text { mestrado em } \\
\text { Educação. }\end{array}$ & $\begin{array}{l}\text { Professora no Colégio } \\
\text { Marista Graças; } \\
\text { orientadora educacional } \\
\text { no Colégio Marista } \\
\text { Graças; } \\
\text { vice-diretora no Colégio } \\
\text { Marista Assunção; } \\
\text { Gerente educacional dos } \\
\end{array}$ \\
& & & $\begin{array}{l}\text { Golégios da Rede } \\
\text { Marista }\end{array}$ \\
\hline
\end{tabular}

Fonte: Elaborado pela autora (2016)

Para a apuração da pesquisa documental e das entrevistas utilizou-se a técnica de análise de conteúdo, a qual se caracteriza por um método de pesquisa que visa a objetividade: explicação das regras e dos procedimentos utilizados em cada etapa da análise de conteúdo, pela qual se busca minimizar a possibilidade de que os resultados sejam reflexos da subjetividade do pesquisador; sistematização: inclusão ou exclusão do conteúdo ou categorias de um texto de acordo com regras consistentes e sistemáticas; interferência: operação pela qual se aceita uma proposição em virtude de sua relação com outras proposições já aceitas como verdadeiras (Richardson, 1999).

\section{Análise dos dados}

Fundado em 1817, no vilarejo de La Valla, na França, por Marcelino Champagnat, o Instituto dos Irmãos Maristas atende hoje mais de seiscentas e cinquenta mil crianças, jovens e adultos, espalhados por, aproximadamente, 85 países dos cinco continentes. 0 Instituto está vinculado à Igreja Católica Romana e tem por missão a evangelização de crianças, jovens e adultos por meio da educação.

No Brasil, conforme dados institucionais, o Instituto possui uma das mais representativas atuações, somando $42 \%$ de toda a presença Marista no mundo. Dentro do território nacional a instituição está dividida em três unidades administrativas: Província Marista Brasil Centro-Norte - PMBCN; Província Marista Brasil Centro-Sul - PMBCS - e Província Marista Brasil Sul-Amazônia - PMBSA -, que formam o Brasil Marista. Este trabalho foi desenvolvido nos colégios pagos da Província Marista Brasil Sul-Amazônia.

A Rede Marista é o nome comercial da PMBSA. A liderança da Rede Marista é do irmão Inácio Etges, o qual tem o cargo de provincial e presidente e conta com o apoio de mais sete irmãos maristas que formam o Conselho Provincial. Além disso, as funções administrativas, educacionais e assistenciais da Rede Marista estão divididas em três mantenedoras de direito privado, sem fins lucrativos e de caráter filantrópico: Sociedade Meridional de Educação - Some -, União Sul Brasileira de Educação e Ensino - Usbee - e União Brasileira de Educação e Assistência - Ubea. Dentro da estrutura de gestão e administração da Rede Marista estão os colégios e unidades sociais, o hospital São Lucas - HSL - e a Pontifícia Universidade Católica do Rio Grande do Sul - PUCRS.

No âmbito da educação básica a Rede Marista incorpora duas mantenedoras: Some e Usbee, as quais gerem vinte e seis colégios, sendo que dezoito deles são pagos dezessete estão localizados no estado do Rio Grande do Sul e um em Brasília/DF - e oito gratuitos. Atendem a mais de vinte mil estudantes de educação infantil, ensino fundamental, ensino médio e educação de jovens e adultos. 
A Rede Marista possui diversos setores que fazem o gerenciamento das atividades e garantem o suporte administrativo das escolas. A sede dos colégios da Rede Marista, estabelecida em Porto Alegre, conta com superintendência, escritório de projetos, assessoria de comunicação e marketing, assessoria jurídica, gerência educacional, gerência social e gerência operacional. Destes, a gerência educacional é a responsável pela operação dos dezoito colégios pagos.

A realização deste estudo aconteceu no contexto das dezoito escolas pagas que oferecem educação infantil, ensino fundamental e ensino médio, sendo dois colégios escolhidos como amostragem. Ambos os colégios estão localizados na cidade de Porto Alegre/RS e praticam um modelo de gerenciamento triplo, com um diretor geral, um vicediretor administrativo e outro vice-diretor educacional, entretanto, suas características de atuação e cenário mercadológica configuram-se de maneira muito diferente.

O Colégio Marista Champagnat localiza-se no campus central da PUCRS, usufruindo de toda a segurança, modernidade e qualidade da universidade. A escola possui uma área de quase quatro mil metros quadrados para atender cerca de 1.200 estudantes de 3 à 17 anos de idade. O quadro funcional é composto por, aproximadamente, 140 servidores: professores, técnico-administrativos e gestores.

Foi criado em 1920 e possui uma trajetória reconhecida. Por estar inserido no cotidiano acadêmico da PUCRS os estudantes são motivados para pesquisa desde os primeiros anos da educação infantil e existe um acompanhamento vocacional para fidelização dos alunos na universidade quando finalizam o ensino médio. O planejamento estratégico do Colégio Marista Champagnat foi desenvolvido com foco em reposicionamento e liderança de mercado, a partir de diferenciação de mercado e da tradição educacional de mais de 95 anos de atuação.

Já o Colégio Marista Ipanema conta com cerca de 120 pessoas, que atendem a mais de 900 estudantes de 4 à 17 anos de idade. O colégio foi fundado no ano de 2007. O planejamento estratégico do Colégio Marista Ipanema foi desenvolvido com foco em reposicionamento e ocupação de mercado, a partir de uma proposta inovadora e do fortalecimento da reputação e imagem do colégio.

Foram analisadas as informações obtidas pelas entrevistas semiestruturadas com superintendente e gerente educacional destes dois colégios da Rede Marista. A pesquisa documental envolveu: Manual do planejamento estratégico dos colégios da Rede Marista; Regimento escolar dos Colégios Marista Champagnat e Ipanema; O diretor marista e sua gestão à serviço da missão: orientações para a formação dos diretores na América Marista e o Projeto educativo do Brasil Marista. Procurou-se identificar a coerência entre os dados coletados e a literatura referenciada.

Nos colégios da Rede Marista o planejamento estratégico formal está em sua terceira versão, desde sua fundação os colégios possuem cultura de planejamento de suas ações. O Instituto Marista é organizado a partir de triênios de gestão, que possuem diretrizes de ação para eixo de atuação da organização.

De acordo com o Manual do planejamento estratégico dos colégios da Rede Marista, identifica-se que todo o processo de planejamento estratégico foi elaborado a partir de uma equipe multidisciplinar. O grupo buscou desenvolver o material para atender ao 
chamado da missão essencial do Instituto Marista: evangelizar por meio da educação. A ideia do documento se traduz na atualização desta missão por meio de desafios concretos em um novo tempo para educação.

O planejamento está alicerçado na sistemática do balanced scorecard - BSC - e visa a um horizonte de dez anos (2022) com revisão em cinco anos (2017). O BSC consiste em um método que organiza de forma balanceada os objetivos e indicadores de uma instituição e suas ligações de causa-e-efeito a partir das quatro perspectivas: financeiro, clientes, processos internos, aprendizado e crescimento (Kaplan; Norton, 1997).

O Manual do planejamento estratégico dos colégios da Rede Marista descreve todo o desdobramento e construção do plano estratégico. O documento narra sobre a necessidade da profissionalização da gestão no setor educacional. Este aspecto também foi mencionado por dois dos entrevistados quando relataram que para a gestão escolar eficaz não bastam somente a boa vontade e o velho tino administrativo. $O$ setor educacional competitivo requer um posicionamento estratégico adequado para que a organização alcance sua visão de futuro.

Em seu relato um dos entrevistados apontou a importância da elaboração da matriz Swot para o desenvolvimento do planejamento estratégico dos colégios da Rede Marista. O Manual do planejamento da instituição também registra esta etapa como fundamental para definição do futuro de uma instituição. Como fase de diagnóstico que antecipa a elaboração do planejamento estratégico, a análise Swot pode ser definida como um sistema simplificado que busca identificar a posição estratégica da empresa frente ao seu mercado e, consequentemente, seu ambiente de atuação. (Kotler; Keller, 2006).

Durante as entrevistas, bem como nos documentos analisados, ficou evidente que este planejamento dos colégios da Rede Marista foi desenvolvido conforme as diretrizes do planejamento estratégico da Província Marista Brasil Sul-Amazônia e que cada um dos dezoito colégios elaborou o seu plano na perspectiva do plano dos colégios da Rede Marista. A redação da missão do planejamento estratégico dos colégios da Rede Marista descreve uma educação evangelizadora, inovadora e criativa que busca a formação de cidadãos transformadores da sociedade.

A visão do empreendimento relata a educação integral e a busca pela liderança em rede, com foco na excelência e crescimento sustentável. Os valores institucionais estão replicados da PMBSA: amor ao trabalho, espiritualidade, audácia, solidariedade, espírito de família, simplicidade e presença (Rede de Colégios e Unidades Sociais da Província Marista do Rio Grande do Sul, 2012).

Em relação à missão dois dos entrevistados apresentaram clareza nas respostas e os demais explanaram a missão geral do Instituto Marista sem a ênfase nos elementos específicos dos colégios da Rede Marista. Em se tratando dos valores e da visão todos os entrevistados citaram os principais elementos norteadores

"Nossa (referindo-se aos Colégios da Rede Marista) visão é bastante audaciosa, pois definimos que queremos ser rede líder em educação integral. Assim, os dezoito colégios possuem uma grande responsabilidade para que, juntos, como rede, possamos alcançar este grande objetivo [...] Falando dos valores, nós reforçamos os valores da nossa Província e não poderia ser diferente." (Entrevistado D, 2016) 
Neste mesmo sentido, Certo e Petter (1993), denominam a estratégia organizacional como forma de alcançar objetivos globais da empresa. Existem algumas estratégias que podem ser adotadas pelas instituições: estratégia de crescimento, estratégia de concentração de atuação, estratégia de estabilidade, estratégia de redução de custos. Também é possível a composição de estratégias para que a empresa alcance seus objetivos gerais.

Um dos entrevistados relatou sobre o detalhamento da visão de maneira pragmática e bastante contundente, destacando os cinco objetivos estratégicos que serão a base para atingi-la: desenvolver pessoas, inovar nas metodologias e tecnologias, obter excelência acadêmica e nos serviços prestados, garantir o relacionamento com os públicos e crescer com sustentabilidade. Tahizawa e Resende (2000) apontam um direcionamento, de acordo com o entrevistado, de que o planejamento estratégico é uma ferramenta que busca a sistematização e organização de atividades com vistas ao alcance dos objetivos, para alcançar um futuro almejado.

O regimento escolar é o documento que elucida a organização administrativa e pedagógica de um estabelecimento de ensino. Formado por normas, orientações, combinações e regras que determinam os direitos e deveres de todos os participes da comunidade educativa, o regimento é a descrição da legalidade da instituição educacional.

Nos artigos 23 e 24 dos regimentos escolares dos Colégios Maristas Champagnat e Ipanema são apresentadas trinta e uma atribuições do diretor escolar, como: "O diretor, representante legal da entidade mantenedora, nomeado pela mesma, dirige, coordena e supervisiona as atividades administrativas e técnico-pedagógicas do estabelecimento de ensino" (Colégio Marista Champagnat, 2015, p. 15).

Cabe ressaltar que apenas um dos entrevistados demonstrou domínio ao pontuar e resumir a intencionalidade dos itens abordados no documento, afirmando que "em linhas gerais o regimento diz que o diretor deve coordenar todos processos (tratando-se dos processos administrativos e pedagógicos) e liderar as pessoas (estudantes, professores e funcionários)" (Entrevistado B, 2016).

Sendo assim, Gomes (2003) pontua a responsabilidade do diretor escolar em garantir que a instituição cumpra a sua missão, a partir de uma gestão efetiva, assegurada pelo pleno exercício de sua liderança. A tarefa de liderar foi mencionada por todos entrevistados, principalmente em relação ao Conselho Técnico-Administrativo Pedagógico - CTAP -, que é a equipe diretiva, de característica tática, que apoia o diretor na gestão compartilhada. $\mathrm{O}$ documento apresenta as palavras "convocar, coordenar e presidir" ao referir-se às obrigações do diretor em relação a este grupo.

Neste mesmo sentido, Lück (2010) destaca o diretor como a principal liderança escolar. O exercício de sua função se concretiza, de maneira participativa, na coordenação, orientação e mobilização de toda a comunidade educativa. A narrativa de um dos entrevistados evidencia a importância do modelo de condução do diretor em relação ao Ctap: "O Ctap é o braço direito do diretor. O jeito que ele (referindo ao perfil do diretor escolar) dirige esta equipe é fator fundamental para uma excelente gestão dos demais membros da comunidade, seus processos e interfaces" (Entrevistado A, 2016). 
Outro aspecto abordado por todos os entrevistados foi a necessidade do diretor ter uma forte identificação com a filosofia Marista, o que também é ressaltado no regimento de maneira mais ampla, citando a fidelização aos princípios de Marcelino Champagnat e da Igreja Católica. Em relação à sua missão como líder o diretor escolar deve gerir os processos à luz do legado de Champagnat, para tornar Jesus Cristo conhecido e amado, ao estilo de Maria (Subcomissão de Formação de Diretores Maristas da América, 2014).

Do ponto de vista educacional dois dos entrevistados expuseram sobre a garantia do ensino e aprendizado dos estudantes como uma das principais tarefas do diretor escolar. O regimento apresenta este item como a atribuição de "coordenar o desenvolvimento do processo educacional, zelando pelo cumprimento do Projeto Educativo" (Colégio Marista Champagnat, 2015, p. 15).

Aspectos abordados no documento como zelar pelo patrimônio institucional, representação legal frente a sociedade e órgãos públicos, garantir espaços de planejamento e desenvolvimento dos educadores, implantar as políticas e diretrizes da mantenedora foram ressaltados e exemplificados por dois dos entrevistados. Todavia, nenhum dos entrevistados pontuou os itens de acompanhamento orçamentário, aplicação de penalidades previstas no regimento e a fomentação de intercâmbio com outras instituições de ensino (Colégio Marista Ipanema, 2015). Estas questões aparecem como atribuições diretas do diretor escolar no regimento dos dois colégios pesquisados.

É relevante salientar que três dos quatro entrevistados demonstraram dificuldade de dissociar as tarefas do cargo de diretor de seu comportamento frente a estas atribuições. Quando questionados em relação às obrigações da atividade de diretor, de forma geral, os entrevistados revelaram um nível de subjetividade ampliado e certo embaraço para sistematizar suas respostas.

Como instrumento administrativo de recursos humanos o perfil de cargo é um instrumento de importante para a gestão estratégica de pessoas. Ao determinar o perfil de algum cargo é crucial o detalhamento das atribuições, responsabilidades, requisitos, competências, habilidades e relações envolvidas. Outra questão preponderante é a análise do ambiente no qual o cargo está submetido (Resende, 1991).

Em relação ao cargo de diretor escolar dos colégios da Rede Marista, entendendo-o como gestor principal do colégio, o Projeto Educativo do Brasil Marista, que aborda as diretrizes políticas-pedagógicas das provinciais do Brasil Marista, descreve o perfil de cargo idealizado para o profissional que atue nesta desafiadora tarefa de gerenciar uma escola.

De maneira geral, o documento aponta as premissas básicas para um gestor Marista, tais como: competências técnicas administrativas e pedagógicas; trato no relacionamento interpessoal; comunicação clara e precisa; capacidade para negociar; habilidade para trabalhar em equipe, aptidão para a gestão estratégica e gestão de projetos; proposição para inovação e melhoria contínua (União Marista do Brasil, 2010). Da mesma forma, os quatro entrevistados dissertaram sobre estes itens básicos de gestão que o Projeto educativo aborda.

A publicação $O$ diretor marista e sua gestão a serviço da missão é um documento comum aos colégios da região da América do Sul que também direciona o perfil do diretor escolar marista. O trecho abaixo revela a intencionalidade do documento, buscando uma maior profundidade para descrever esta configuração: 
A Missão de um Diretor Marista deixa clara, aos diretores contemporâneos, a necessidade de percepção e atenção sobre o que é relevante. É uma tarefa complexa, considerando a quantidade e demandas sobrepostas pelo mundo atual. A civilização deste milênio caminha a passos longos em direção à reconexão, à acolhida e à inclusão (Subcomissão de formação de diretores maristas da América, 2014, p. 28)

Todos os entrevistados citaram a abertura para dialogar com a comunidade escolar e as habilidades relacionais como premissas na definição do perfil de um diretor escolar. O projeto educativo reforça este tópico retratando a necessidade do diretor atuar positivamente no clima organizacional, por meio de relações saudáveis, e na negociação de conflitos. Pensando nas especificidades de ser um gestor marista "é crucial perceber que a evangelização materializada pelo exemplo, no testemunho comprometido, acolhedor, disponível para compartilhar valores cristãos quando integra o diálogo e as inter-relações" (Subcomissão de formação de diretores maristas da América, 2014, p. 29).

Dois dos entrevistados sinalizaram que o diretor escolar deve ser orientado para resultados. Um dos entrevistados utilizou o termo empreendedor para caracterizar o perfil de um diretor escolar marista. Peter Drucker (1987) descreve o empreendedor como aquele que desenvolve algo novo, diferente. É uma pessoa que propõe a mudança, a transformação, que agrega valor, busca inovação e cria oportunidades.

O Projeto educativo do Brasil Marista retrata o gestor escolar como um empreendedor que precisa estar atento aos cenários, identificando desafios e garantindo a perenidade de sua escola à luz dos seus resultados. Saber analisar estes resultados para melhoria continua dos processos escolares e proposição de metodologias inovadoras é essencial para este nível de gestão. A manifestação de um dos entrevistados relata o significado deste ponto: "Um diretor que é orientado para resultados tem a capacidade de enxergar os avanços e os pontos de melhoria, tanto do seu desempenho, como da sua equipe. Ele não é muito apegado nas tarefas, mas busca fazer entregas de excelência, sempre melhorando seus processos" (Entrevistado C, 2016).

A habilidade de liderar e motivar as pessoas foi apontada por três entrevistados como um fator fundamental para um diretor. Lück (2009) destaca que este profissional é a figura de máxima liderança em uma escola, portanto, sua forma de atuação e seu perfil tem impacto no cotidiano do colégio. Um dos entrevistados classificou o diretor escolar como um líder corajoso, pelo fato de assumir responsabilidades em relação à formação dos estudantes. Outro entrevistado categorizou a liderança como um estado de autoavaliação contínua do diretor, pensando no seu papel estratégico e influenciador de diferentes públicos (Limongi-França; Arrelano, 2002).

A vivência da espiritualidade Marista, revelada no perfil do diretor, foi mencionada por todos os entrevistados. O documento sobre a gestão do diretor a serviço da missão retrata este aspecto durante todos os seus capítulos, apresentado a espiritualidade Marista com foco no estilo de ser de um gestor educacional evangelizador. Para os maristas o caráter mariano é a essência para atingir os objetivos da missão de Champagnat: tornar Jesus Cristo conhecido e amado. 
Outro tema assinalado por dois dos entrevistados foi a visão sistêmica, ou seja, a capacidade de percepção e apropriação do todo. Desta mesma forma, os dois documentos analisados abordam a visão sistêmica como um elemento substancial no perfil do diretor, principalmente ao tratar de dimensões pastorais, pedagógicas e administrativas, que se distinguem quando a sua natureza.

Também foram referidos a maturidade, o equilíbrio emocional, a sensibilidade, a empatia, a compreensão, o carisma e o bom humor como pontos relevantes ao perfil do diretor. Para um gestor escolar observa-se a importância de um perfil apaixonado pela sua função, que tenha consciência de outras realidades e amor pelas pessoas (Handy, 1996). Por conseguinte, cabe o destaque para o relato de dois entrevistados que se manifestaram com um grau perceptível de emoção quando falaram sobre estes temas: "Se dez vidas eu tivesse, dez vidas eu daria pela educação, porque eu gosto de estar com gente [...]. Eu gosto de formar gente. Eu sou gente porque convivo com outras gentes (risos)" (entrevistado D, 2016).

O documento Missão educativa marista: um projeto para nosso tempo, resume o perfil do diretor escolar marista como um gestor que é desafiado a olhar para o futuro e vivenciar os valores maristas, sendo um formador de novos maristas. O diretor escolar marista é um representante de São Marcelino Champagnat para a sua comunidade educativa. Ele deverá conduzir o seu colégio com confiança, otimismo e determinação, alicerçado na espiritualidade apostólica mariana (Comissão Interprovincial de Educação Marista, 2003).

A matriz que descreve o núcleo de formação para um diretor marista, que foi elaborado pela Subcomissão de Formação de Diretores Maristas da América no ano de 2014. Esta publicação é recente e a implantação está em processo de internalização dos principais gestores da Rede Marista. Entretanto, sua contribuição e qualidade são importantes para o aprimoramento das competências comportamentais dos diretores dos colégios maristas.

Do ponto de vista de rede de colégios os quatro entrevistados demonstraram muita perspicuidade quanto ao papel colaborativo e contributivo do diretor escolar frente ao planejamento estratégico do empreendimento colégios da Rede Marista. Ficou evidenciado que, tratando-se de trabalho em rede, o todo é maior que o somatório das partes. A narrativa de um dos entrevistados elucida esta compreensão: "Se pensarmos numa rede (fazendo analogia a rede de pesca), existem vários nós que estão interligados e que se relacionam. Se algum desses nós arrebentar, poderá comprometer o resultado final do todo [...]. Se um dos colégios alcançar resultados expressivos e positivos, a rede toda é alavancada" (Entrevistado D, 2016).

Dentro desta linha, Neves (2009) pontua que as redes de trabalho também são consideradas sistemas organizacionais com a capacidade de reunir indivíduos e instituições. Este agrupamento foi estruturado de forma compartilhada, visando ao alcance de objetivos comuns.

Três entrevistados assinalaram que o diretor é o representante da mantenedora em sua unidade, sendo sua corresponsabilidade o sucesso do planejamento estratégico dos colégios da Rede Marista. Neste mesmo sentido, o projeto educativo descreve que o diretor é o principal implementador das políticas e diretrizes da mantenedora e cabe a ele o dever de zelar pela marca institucional, garantindo a atuação em rede. 
Do ponto de vista da execução do planejamento estratégico, Oliveira (2008) ressalta que para implantar uma estratégia é fundamental que as principais lideranças da organização se responsabilizem pelo processo. Assim, quando abordada a perspectiva escolar, o diretor escolar foi apontado nas entrevistas como peça fundamental para execução das estratégias e garantia da sistematização do planejamento estratégico.

Dois dos entrevistados abordaram que o diretor é o principal ator do colégio e não poderia estar em segundo plano em se falando de planejamento estratégico. Esta afirmação evidencia-se no trecho de uma das entrevistas: "O planejamento estratégico é uma das coisas mais importantes no colégio, portanto, algo de grande importância, precisa ficar sobre a gestão da pessoa mais importante no colégio: o diretor" (Entrevistado A, 2016).

O documento $O$ diretor marista e sua gestão a serviço da missão destaca o planejamento estratégico como um dos núcleos de atuação do diretor escolar marista. A publicação refere-se ao tema como uma metodologia que orienta e dirige o colégio, a partir de uma perspectiva de autonomia responsável e responsabilidade compartilhada.

No que se refere ao planejamento estratégico existem expectativas quanto à atuação do diretor descritas no documento. A primeira delas trata da coerência entre a missão institucional, as pessoas, os processos e os resultados que devem ser evidenciados a partir da evangelização. A segunda diz respeito à clareza nas metas $\mathrm{e}$ forma de trabalho, que deve ser tanto individual, quanto inserido nas equipes. A terceira expectativa aborda a melhoria continua instalada como atitude institucional, a partir da ação cotidiana do diretor escolar (Subcomissão de Formação de Diretores Maristas da América, 2014)

$\mathrm{Na}$ concepção da gestão estratégica um dos entrevistados destacou o papel do diretor perante o planejamento estratégico do seu colégio, como um articulador e controler. Ou seja, o diretor deverá garantir o alinhamento entre a operação, as pessoas e os objetivos do planejamento estratégico, bem como, precisa monitorar e fiscalizar as opções estratégicas adotadas no plano.

A liderança, como fundamentação do papel do diretor, também foi citada por dois entrevistados. Bossidy (2005) aponta que um plano estratégico que conta com a presença do líder principal tende a ter maior sucesso na execução. O diretor é a pessoa que conduz a organização ao alcance dos objetivos, portanto, é necessário que ele assuma uma postura de líder de executor frente a este assunto: "O lugar do diretor é de líder principal do planejamento estratégico. Ele precisa contagiar sua equipe, delegar as tarefas e acompanhar o planejamento. Eu penso que isso é o principal trabalho do diretor em um colégio" (Entrevistado C, 2016).

A motivação da comunidade escolar, no que diz respeito ao planejamento estratégico, também foi indicado como um item ligado ao diretor. Dois dos entrevistados pontuaram que um líder estratégico precisa contagiar os demais envolvidos no processo. Um deles destacou que o diretor não tem o direto de desanimar frente ao planejamento estratégico mas, ao contrário, precisa acreditar na metodologia e garanti-la como pauta prioritária de sua gestão. 
Aspectos como protagonismo, autoria e intenção também foram citados pelos entrevistados quando questionados do papel do diretor frente ao planejamento estratégico de seu colégio. Dois entrevistados disseram que o diretor é o grande guardião do plano estratégico do seu colégio, sendo ele a pessoa que aguerridamente defende a ferramenta frente à comunidade escolar.

Durante o diálogo das entrevistas ficou notório que o papel do diretor, em se tratando de planejamento estratégico, é assegurar a execução das intencionalidades registradas em seu plano norteador: visão e objetivos estratégicos. O diretor precisa, além de participar e gerir o processo de fundamentação dos desejos do colégio, converter estes latejos em ações executáveis e que possam ser acompanhadas (Csikszentmihaly, 2001).

Hrebiniak (2006) também se refere à execução do planejamento estratégico como um desafio para liderança de uma organização. Logo, no cotidiano escolar, que possui uma hierarquia evidenciada pela verticalidade dos cargos, o diretor é o elemento crucial na execução do planejamento estratégico.

É visto que o trabalho do diretor escolar, enquanto gestor educacional, é bem mais complexo do que qualquer lista de atribuições descritas em manuais organizacionais. A dinamicidade de um colégio exige do diretor o "exercício de múltiplas competências específicas" (Lück, 2009, p. 25).

Quando se trata da gestão educacional à luz do planejamento estratégico, estas variáveis se tornam ainda mais emaranhadas. O papel do diretor escolar neste contexto apresentado é profundo e abrangente, com foco prevalecente nas pessoas participantes da escola: pais, estudantes, professores, parceiros e colaboradores. A promoção de um clima de confiança, cooperativismo, valorização e motivação é a chave para integrar esforços, sistematizar resultados e desenvolver a prática da corresponsabilidade rumo aos objetivos estratégicos do colégio (Lück et al, 2005).

\section{Considerações finais}

As escolas, dentro de um contexto de mercado educacional, iniciaram um processo de profissionalização da gestão. Preocupações com planejamento estratégico, visão de mercado e orientação para resultados, passaram a fazer parte do cotidiano dos diretores, que representam a gestão escolar. Do ponto de vista do planejamento estratégico o maior desafio que se apresenta é a execução daquilo que foi descrito e almejado em sua elaboração. A forma de monitoramento da execução dos objetivos estratégicos é o BSC, que é acompanhado sistematicamente. As diretrizes do planejamento estratégico são bem entendidas e compreendidas pelos principais gestores dos colégios da Rede Marista e o modelo de corresponsabilidade é uma realidade do ponto de vista da implantação das estratégias.

O regimento escolar é o principal documento sobre o modelo de organização formal do colégio e, principalmente, sobre as rotinas e tarefas, direitos e deveres de cada participante da comunidade escolar. Os entrevistados não foram unânimes quanto às atribuições de um diretor escolar e três deles mesclaram as atribuições de cargo com perfil comportamental durante suas narrativas. Todavia, em se tratando de atribuições, o regimento escolar é direto e objetivo quando apresenta o diretor como o responsável geral e legal sobre todos os processos que acontecem no colégio. 
Verificou-se que o empreendimento colégios da Rede Marista, não dispõe de uma descrição formal para o cargo em questão. Atualmente existe um projeto estratégico que compreende em seu escopo a descrição de perfil de cargos.

$\mathrm{O}$ projeto educativo apresentou-se como um documento institucionalizado e direcionador quanto ao perfil dos gestores, apesar de abordar o assunto de forma superficial, com pouco aprofundamento das competências inerentes ao cargo. A publicação $O$ diretor marista e sua gestão a serviço da missão é um documento aprofundamento, principalmente no que diz respeito à cultura organizacional e propósitos da gestão marista, entretanto, ainda não está internalizado dado ao seu recente lançamento. Embora a organização não tenha sua descrição formal de perfil de cargo, as repostas dos entrevistados foram bastante alinhadas aos documentos existentes e as competências comportamentais foram apontadas como fator determinante no sucesso da gestão escolar.

As respostas dos entrevistados foram homogêneas quando questionados sobre papel do diretor à luz da execução do plano estratégico: primordial, essencial e fundamental. $O$ diretor escolar não só tem a função de coordenar e controlar 0 planejamento estratégico do seu colégio, mas tem a tarefa de liderar todos os envolvidos em busca de objetivos comuns que além de alavancar a operação de sua escola, contribuam para o desenvolvimento, crescimento e consecução das metas do empreendimento colégios da Rede Marista. Durante a investigação ficou nítido o entendimento de todos os gestores entrevistados frente à atuação em rede para fortalecimento da marca e perenidade da atuação.

Sendo assim, o presente trabalho foi relevante do ponto de vista gerencial, contribuindo para a profissionalização da organização e a legitimação dos documentos e manuais em relação à atuação dos diretores e gerando indicações para afiançar a execução de seu plano estratégico.

Como sugestão para estudos futuros indica-se uma pesquisa de análise dos objetivos estratégicos dos colégios da Rede Marista e as iniciativas estratégias definidas para alcançá-los, uma avaliação de perfil dos diretores a partir das proposições do plano estratégico e um estudo sobre o impacto do perfil comportamental do diretor escolar frente ao alcance das metas do plano estratégico.

\section{Referências}

ALMEIDA, Martinho Isnard Ribeiro de. Manual de planejamento estratégico. São Paulo: Atlas, 2001.

BENNIS, Warren. A formação do líder. São Paulo: Atlas, 1996.

BOONE, Louis.; KURTZ, David. L. Marketing contemporâneo. 8. ed. Rio de Janeiro: LTC, 1998.

BOSSIDY, Larry. A receita da execução. HSM Management, v. 4, n. 51, Ano 9, p. 40-44, jul./ago., 2005.

BOSSIDY, Larry; CHARAN, Ram. Desafio: fazer acontecer, a disciplina de execução nos negócios. 3. ed. Rio de Janeiro: Negócio Editora, 2002.

BRANDÃO, Carlos Rodrigues. O que é educação. 28. ed. São Paulo: Brasiliense, 1993. 
CERTO, Samuel C.; PETER, J. Paul; STEFFEN, Flavio Deni. Administração estratégica: planejamento e implantação da estratégia. São Paulo: Makron Books, 1993.

COLÉGIO MARISTA CHAMPAGNAT. Regimento Escolar: educação infantil, ensino fundamental e ensino médio. Porto Alegre, 2015 (Documento interno).

COLÉGIO MARISTA IPANEMA. Regimento Escolar: educação infantil, ensino fundamental e ensino médio. Porto Alegre, 2015 (Documento interno).

COMISSÃO INTERPROVINCIAL DE EDUCAÇÃO MARISTA. Missão educativa Marista: um projeto para nosso tempo. Tradução Manoel Alves e Ricardo Tescarolo. 3. ed. São Paulo: Simar, 2003.

CORUS CONSULTORES. Infraestrutura em escolas: uma preocupação pertinente. [São Paulo]: Corus Consultoria, [s.d.]. Disponível em: <http://corusconsultores.com.br/corus_art22.pdf>. Acesso em: 17 mar. 2013.

CSIKSZENTMIHALYI, Mihaly. "O contexto da criatividade". In: BENNIS, Warren; SPREITZER,

Gretchen; CUMMINGS, Thomas G. (Orgs.). O futuro da liderança. São Paulo:

Futura, p. 132- 140, 2001.

DEMO, Pedro. Educar pela pesquisa. Campinas: Autores Associados, 1996.

DRUCKER, Peter F. Inovação e espírito empreendedor. São Paulo: Pioneira, 1987.

FREITAS, Maria Ester. Cultura Organizacional: formação, tipologias e impacto. São Paulo: McGraw-Hill Ltda, 1991.

GIL, Antônio Carlos. Como elaborar projetos de pesquisa. São Paulo: Atlas, 1996.

GOMES, Delarim Martins. Competências e habilidades do diretor. Campo Grande: UCDB, 2003.

GRÜN, Anselm. A sabedoria dos monges na arte de liderar. Petrópolis: Vozes, 2006.

HANDY, Charles. "A nova linguagem da administração e suas implicações para os líderes”. In: DRUCKER, Peter F. O líder do futuro. 7. ed. São Paulo: Futura, 1996.

HREBINIAK, Lawrence. G. Fazendo a estratégia funcionar: o caminho para uma execução bem-sucedida. Rio Grande do Sul: Bookman, 2006.

HUNTER, James. Como se tornar um líder servidor. Rio de Janeiro: Sextante, 2006.

KAPLAN, Robert S.; NORTON, David P. A estratégia em ação: balanced scorecard. Gulf Professional Publishing, 1997.

KATZ, Daniel; KAHN, Robert L. Psicologia das organizações. São Paulo: Atlas, 1987.

$\mathrm{KICH}$, Juliane Ines Di Francesco et al. A influência do líder na condução do processo de implementação do planejamento estratégico. Revista de ciências da administração, v. 10, n. 21, p. 122-146, 2008.

KOTLER, Philip; KELLER, Kevin Lane. Administração de marketing. 2006.

LACOMBE, Francisco. Recursos humanos: princípios e tendências. São Paulo: Saraiva, 2005.

LIBÂNEO, José Carlos. Organização e gestão da escola: teoria e prática. 5. ed. Goiânia: Alternativa, 2004.

LIMONGI-FRANÇA, Ana Cristina; ARELLANO, Eliete Bernal. Qualidade de vida no trabalho. 2. ed. São Paulo: Gente, 2002. 
LÜCK, Heloísa. Dimensões da gestão escolar e suas competências. Porto Alegre: Positivo, 2009.

LÜCK, Heloísa. Liderança em gestão escolar. 6. ed. Porto Alegre: Vozes, 2010.

LÜCK, Heloisa et al. A escola participativa: o trabalho do gestor escolar. Petrópolis: Vozes, 2005.

MARCONI, Marina de Andrade; LAKATOS, Eva Maria. Fundamentos de metodologia científica. 6. ed. São Paulo: Atlas, 2007.

MENOSSI, Marino; et al. Gestão educacional: marketing, pessoas e finanças: os pilares para uma gestão de sucesso. São Paulo: Viena, 2012.

MINTZBERG, Henry; LAMPEL, Joseph ; AHLSTRAND, Bruce. Safári de Estratégia. Porto Alegre: Bookman, 2007.

NEVES, Marília Nogueira. O serviço social e o atendimento em rede. ㄴo Simpósio Mineiro de Assistentes Sociais - Anais. Belo Horizonte, 2009, p. 43-62.

OLIVEIRA, Djalma de Pinho Rebouças. Planejamento estratégico: conceitos, metodologia, praticas. São Paulo: Atlas, 2008.

PEREIRA, Maurício Fernandes; CUNHA, Myriam Siqueira. Os aspectos da cultura organizacional em um processo de gestão não materialista. In: LANER, Aline dos Santos; CRUZ JÚNIOR, João Benjamim da. Repensando as organizações - da formação à participação. Florianópolis: Fundação Boiteux, 2004, p. 317-338.

PETERSON, Steven; TIFFANY, Paul. Planejamento estratégico. Rio de Janeiro: Campus, 1998.

RESENDE, Ênio. Cargos, salários e carreira. Grupo Editorial Summus, 1991.

REDE DE COLÉGIOS E UNIDADES SOCIAIS DA PROVÍNCIA MARISTA DO RIO GRANDE DO SUL. Manual Executivo do Planejamento Estratégico. Porto Alegre, 2012 (Documento interno).

RICHARDSON, Roberto Jarry. Pesquisa social: métodos e técnicas. 3. ed. São Paulo: Atlas, 1999.

ROESCH, Sylvia Maria Azevedo. Projetos de estágio e de pesquisa em administração: guia para estágios, trabalhos de conclusão, dissertações e estudos de caso. 3. ed. São Paulo: Atlas, 2005.

SEMLER, Ricardo. Virando a própria mesa. São Paulo: Best Seller, 1988.

SUBCOMISSÃO DE FORMAÇÃO DE DIRETORES MARISTAS DA AMÉRICA. O diretor Marista e sua gestão a serviço da missão: orientações para a formação dos diretores da América Marista. 2014 (Documento interno).

TACHIZAWA, Takeshy; REZENDE, Wilson. Estratégia empresarial: tendências e desafios: um enfoque na realidade brasileira. Makron Books, 2000.

TREGOE, Benjamin; ZIMMERMAN, John. A estratégia da alta gerência: o que é e como fazê-la funcionar. 2. ed. Rio de Janeiro: Zahar Editores, 1984.

ULRICH, Dave. Credibilidade x Competência. In: DRUCKER, Peter. O Líder do futuro. 9. ed. São Paulo: Futura, p. 213-222, 2001.

UNIÃO MARISTA DO BRASIL. Projeto educativo do Brasil Marista: nosso jeito de conceber a educação básica. Brasília: UMBRASIL, 2010.

WHITTINGTON, Richard. O que é estratégia. São Paulo: Thomson, 2002. 
YIN, Robert K. Estudo de caso: planejamento e método. 3. ed. Porto Alegre: Bookman, 2005.

ZIKMUND, William. Princípios da pesquisa de marketing. São Paulo: Pioneira Thomson Learning, 2006.

Manoela da Rocha Atarão Saldanha é especialista em Gestão Empreendedora pelo Centro Universitário Ritter dos Reis.

Endereço: Avenida Wenceslau Escobar, 1040 - 91180-430 - Porto Alegre - RS Brasil.

E-mail: mrssaldanha@hotmail.com.

Cristine Hermann Nodari é doutora em Administração pela Pontifícia Universidade Católica do Rio Grande do Sul.

Endereço: Avenida Wenceslau Escobar, 1040 - 91180-430 - Porto Alegre - RS Brasil.

E-mail: cristine.nodari@gmail.com.

Julice Salvagni é doutora em Sociologia pela Universidade Federal do Rio Grande do Sul.

Endereço: Avenida Wenceslau Escobar, 1040 - 91180-430 - Porto Alegre - RS Brasil.

E-mail: julicesalvagni@gmail.com.

Recebido em 6 de março de 2017.

Aceito em 31 de maio de 2017. 